\title{
(t)
}

\section{LA CUMBRE DE LOS PUEBLOS, RIO +20 $Y$ EL BIEN COMUN DE LA HUMANIDAD}

People's Summit, Rio +20 and the common good of mankind

\section{François Houtart ${ }^{1}$}

Cuando 193 países son representados, 120 jefes de Estado están presentes y 17.000 delegados se han reunido, no se trata de cualquier evento. Cuando en paralelo se organiza una Cumbre de los Pueblos con 755 seminarios y se cuenta con la presencia de 300.000 personas, no se trata de un banal encuentro. La reunión de alcaldes de 58 de las mayores ciudades del mundo en el mismo lugar, decidiendo reducir 1,3 billones de toneladas de emisión de $\mathrm{CO} 2$ para 2030, no son señales insignificantes. Símbolo fehaciente: durante 10 días, el Cristo del Corcovado fue iluminado de verde. De verdad el desafío era la supervivencia del planeta y en consecuencia de la humanidad.

La Conferencia de las Naciones Unidas en Estocolmo en 1972 había iniciado este proceso que se prolongó en Río de Janeiro, 1992. El Brasil tomó la iniciativa de promover Río+20, en 2012. Era claro que, frente a la gravedad de la situación se debía acelerar un proceso que necesariamente será de largo plazo. Los países pobres se mostraron los más incumbidos, pidiendo compromisos colectivos precisos. Al contrario, los Estados Unidos de América pensaban que cada país tenía que tomar sus propias iniciativas. Dos temas mayores fueron abordados: la economía verde y el papel de las Naciones Unidas (ONU).

\footnotetext{
${ }^{1}$ Sociólogo e professor da Universidade Católica de Louvain (Bélgica). É diretor do Centro Tricontinental, entidade que desenvolve trabalho na Ásia, África e América Latina. E-mail: <houtart@hotmail.com>.
} 
Para el primer punto, se trataba de incluir dentro de la lógica del mercado, el problema de la naturaleza. En efecto, su destrucción no puede seguir siendo considerada como solamente una "externalidad", es decir un hecho externo al cálculo del mercado, porque empieza a afectar las tasas de ganancias y, en consecuencia, la acumulación del capital. Su "reinserción" se efectuaría a través de tasas impuestas a la contaminación y por la atribución de precios a los elementos y procesos de la naturaleza, como la bio-masa, la biodiversidad, las funciones naturales (polinización, absorción del CO2, etc.) (THEMATIC SOCIAL FORUM, 2012). Ya Kioto había empezado el proceso con el mercado del $\mathrm{CO}_{2}$.

Sin embargo, el pensamiento de la lógica capitalista va más allá. Según Víctor Álvarez, economista venezolano, “Con la 'economía verde', se busca reorientar las inversiones financieras hacia el 'capital natural', pero en esencia se trata de una nueva forma de reactivar y ampliar los mercados especulativos de servicios ambientales que se inauguraron con los certificados de carbono" (ÁLVAREZ, 2012). En otras palabras la economía verde significa la mercantilización de la naturaleza, esperando por este proceso contribuir a un menor despilfarro. El segundo tema fue el papel de las Naciones Unidas y en particular del Programa de Naciones Unidas para el Medio Ambiente (PNUMA), que se esperaba transformar en una agencia de la ONU a la par de la Organización de las Naciones para la Alimentación y la Agricultura (FAO) o de la Organización de las Naciones Unidas para la Educación, la Ciencia y la Cultura (UNESCO).

El documento final El futuro que queremos, que reconoce la gravedad de la situación ambiental, no incluye ningún compromiso colectivo, en parte tomando como argumento la crisis que afecta los países ricos. El "consenso", típico de estas asambleas, fue la organización de un grupo de 30 expertos encargados de estudiar los requisitos de un "desarrollo sostenible" y de presentar un informe para 2014. Por otra parte, el PNUMA no recibió el estatuto de agencia de las Naciones Unidas, pero ha visto extender sus tareas y sus medios. A nombre de 1000 organizaciones ambientales, el portavoz de la "sociedad civil" en el seno de la Asamblea de la ONU, pidió el retiro de la frase "con plena participación de la sociedad civil”, expresando así una profunda decepción. 
Desde Río 1972, la situación empeoró considerablemente: grandes pérdidas de biodiversidad, contaminación de suelos y aguas, catástrofes naturales, inseguridad alimentaria, aumento de los precios, millones de víctimas humanas. Los discursos oficiales reconocieron el hecho, aun si varios expresaban un optimismo tecnológico bastante irrealista. Los países del Sur (el grupo de los 77 -ahora más de 120 - + China) manifestaron la necesidad de una acción inmediata, y fueron muy severos frente a los países industrializados que son los mayores contaminantes de los ecosistemas. Pidieron la constitución de un Fondo Global de 30 mil millones de dólares para la protección del planeta, lo que fue rechazado.

Pero la distancia entre los discursos y las prácticas de los Estados es abismal. En los países del Centro del capitalismo, la resistencia del "mercado" y la fuerza de los lobbies, acelera la mercantilización de la naturaleza, llamada "capitalismo verde". Como los remedios a la crisis financiera dentro de la lógica del mercado terminan empeorando el problema, lo mismo pasa con las soluciones "market friendly" de la destrucción ecológica. La bolsa de carbono de Londres, por ejemplo, desemboca sobre la especulación y sube y baja en función de los intereses del mercado, sin hablar de los numerosos abusos que se cometen en su nombre.

Los países emergentes siguen con el mismo modelo de desarrollo que obliga a ignorar las externalidades. China y el Vietnam tienen planes de crecimiento profundamente destructores de los eco-sistemas. Sus emisiones de $\mathrm{CO}_{2}$ aumentan fuertemente, aunque proporcionalmente están lejos del grado de emisión de los países de la Triada (Estados-Unidos, Europa, Japón); piensan que no hay otra forma de desarrollar las fuerzas productivas y que una etapa verde seguirá. El problema es que los daños al planeta no se calculan en proporciones, sino en cifras absolutas.

El Brasil, anfitrión de la conferencia, que jugó un papel central para obtener un consenso mínimo, evitando así un fracaso público internacional, insistió mucho sobre la responsabilidad colectiva de las naciones. Pero, al mismo tiempo se preparaba en el Parlamento una ley forestal, del agrado de los terratenientes y de las empresas agrícolas nacionales e internacionales, que tendrá efectos negativos para la selva amazónica. Los monocultivos de soya siguen 
penetrando esta última de manera agresiva; se extiende el cultivo de caña de azúcar para producir etanol, a pesar de sus consecuencias: extensión de la frontera agrícola, destrucción de los suelos, condiciones negativas de trabajo y de salud para los trabajadores; las plantaciones de eucaliptus se multiplican en los estados de Rio Grande do Sul y de Minas Gerais; se prevén más de 1000 nuevas represas hidroeléctricas en zonas de alta biodiversidad y de poblaciones indígenas. Según el periódico Brasil do Fato, Brasil es el mayor país consumidor mundial de agrotóxicos, con el $20 \%$ de todos los venenos agrícolas del planeta (TAVARES, 2012). Se aprobó en 2012, una ayuda estatal a la industria automóvil, a causa de la crisis. Todo eso revela poca coherencia entre las palabras y los hechos.

Países del Sur, que tienen un discurso muy radical sobre la relación con la naturaleza no son indemnes de contradicciones. Bolivia, sede en 2010 de la Cumbre sobre el clima y que ha introducido de manera impresionante el tema de la defensa de la "Pachamama", fue también muy activo en Río. Pero, al mismo tiempo, su gobierno promueve la construcción de la carretera a través del TIPNIS (Parque Nacional Isiboro Secure, zona de alta biodiversidad) provocando no solamente las reacciones de los indígenas amazónicos, sino olvidando su responsabilidad global frente a la protección de los pocos lugares de los cuales dispone el planeta para su respiración. En el Ecuador, autor de la propuesta revolucionaria de no explotar el petróleo del parque Yasuní, sí la solidaridad internacional funciona, sigue promoviendo grandes proyectos mineros a cielo abierto, monocultivos de palma y de caña para agro-combustibles, con sus consecuencias ecológicas graves e irreversibles.

Muchos ejemplos similares podrían ser dados en todos los continentes. Es un hecho que los gobiernos son orientados por lógicas a corto plazo. Es muy difícil defender orientaciones a medio y largo plazo, cuando uno debe responder a demandas inmediatas y a elecciones que se realizan cada cuatro años. Es lo que el vicepresidente de Bolivia, Álvaro García Linares indicó en un trabajo sobre las tensiones de un proyecto revolucionario. Eso indica el papel esencial de los movimientos sociales, que pueden pensar a más largo plazo, a condición de no perderse en los procesos electorales, por lo tanto, sin perder su responsabilidad política. 
En la Cumbre de los Pueblos las informaciones sobre las situaciones reales eran abundantes y alarmantes. Sin embargo, al mismo tiempo revelaban el compromiso de miles de movimientos y organizaciones de varios sectores en la defensa del ecosistema. También se notaba la extensión de la preocupación del planeta a nivel mundial. Cinco temas estuvieron en el orden del día: Justicia social y ambiental; defensa del bien común frente a la mercantilización; soberanía energética y alimentaria; energía y minas; otra economía y nuevo paradigma para la sociedad.

Evidentemente muchas de las iniciativas eran locales, a menudo sin muchas interacciones entre ellas mismas y con el peligro de ser aceptables para el sistema, debido a su pequeña dimensión y su escasa incidencia económica y política. Otras tenían una dimensión importante, nacional o internacional, pero tan segmentadas en sus perspectivas, que podían perfectamente coexistir con la hegemonía del mercado al nivel macroeconómico. Sin embargo, la mayoría introducían nuevas visiones del mundo, una nueva ética y una nueva lógica de desarrollo humano.

El gran paso que se hizo en la Cumbre de Río, fue en el nivel de conciencia sobre el problema. No solamente movimientos como el de los indígenas del Continente Americano (DECLARACIÓN..., 2012a), sino también la mayoría de los movimientos ambientales presentes, llegaron a la conclusión de que la causa fundamental del desorden ecológico era la lógica del capitalismo. De hecho, el análisis de varios casos mostraba como la explotación de la naturaleza para alimentar la ganancia y finalmente la acumulación del capital, entraba en contradicción con el respecto a la tierra como fuente de toda vida. Se presentó la Declaración mexicana de la Cumbre de los Pueblos contra el G20 que dice que la causa es: “[... ] el afán desmedido de ganancia, esencia del capitalismo, que en sus últimas décadas se ha tornado especulador, salvaje, depredador y antidemocrático" (DECLARACIÓN..., 2012b). La oposición a una "economía verde", basada únicamente sobre la lógica del mercado, era general. Todo eso tuvo su expresión en la Declaración final, donde se habló de un nuevo ciclo de las luchas globales para liberar el mundo del control del capital financiero y de las falsas soluciones propuestas por Río + 20. Se insistió en el acceso de los pueblos a los bienes y servicios necesarios para la supervivencia y la importancia 
de las iniciativas de economía social para construir un nuevo paradigma de "Buen Vivir".

Por otra parte se decidió la constitución de un órgano de enlace permanente entre los movimientos ambientales, obreros, campesinos, femeninos e indígenas presentes para canalizar información y acciones comunes. Es el principio de una coordinación de fuerzas, entre los principales movimientos sociales, para actuar a nivel mundial.

Un ejemplo concreto del problema ambiental general es el agua. Hubo una tienda llamada "Azul" en el lugar de la Cumbre, donde durante una semana se organizaron conferencias y seminarios sobre este tema. Decenas de especialistas del mundo entero pasaron por allá. Hubo películas e informes técnicos. Se trató de todos los aspectos del problema hídrico contemporáneo.

Los océanos fueron uno de los asuntos abordados. Ellos son más importantes que las selvas para el equilibrio térmico del planeta. Existe una Convención de las Naciones Unidas sobre la ley del mar (UNCLOS) que concierne a la alta mar, es decir al $64 \%$ de los océanos, pero se trata más de la regulación de su explotación que de la responsabilidad de cuidarla. Grandes potencias, como los Estados Unidos se oponen a más regulaciones (TSENIKLI, 2012); la situación se revela inquietante. La polución se extiende por el transporte marítimo y el vertido de desechos, en particular de plásticos. La destrucción de los corales se acelera. El plancton, fuente de alimentación de muchas especies marítimas, desaparece en varias partes de los océanos. La pesca intensiva agota los recursos de peces y las ballenas están en vía de extinción.

El calentamiento de la atmósfera afecta la capacidad de absorción de $\mathrm{CO}_{2}$ por los océanos y provoca el alza de los mares. Esta última empieza a generar problemas en ciertas áreas costaneras, especialmente para grandes ciudades ahí ubicadas. Según el Banco Interamericano de Desarrollo (BID), América latina y el Caribe serán zonas altamente afectadas en los próximos 40 años, con un alza previsible de $2^{\circ}$, significando pérdidas agrícolas de 30 a $52 \mathrm{mil} \mathrm{mi-}$ Ilones de dólares anuales. El continente debería invertir el $2 \%$ de su PIB para reducir la emisión de carbono, es decir 110 mil millones de dólares al año (CLARIN, 2012). 
El agua dulce está también en peligro, tanto por la utilización masiva de productos químicos en la agricultura, como por el consumo urbano. A pesar de que más de dos mil millones de personas en el mundo no tienen acceso a condiciones sanitarias mínimas y que cada día aproximadamente 4.000 niños mueren de enfermedades vinculadas con el agua y la higiene, se continúa con la privatización del agua, como un dogma de la economía de mercado, a favor de grandes empresas transnacionales de producción de bebidas o de distribución de este elemento (AMATYA; SEGUIN, 2012). Ellas producen en condiciones adversas para el medio ambiente y la privatización del agua implica alzas de precios y más exclusión de los más pobres.

La construcción de grandes represas para producir hidroelectricidad provoca enormes destrucciones de ecosistemas. Se citó, en la Cumbre de los Pueblos, un informe del Banco Mundial, diciendo que durante el siglo de desarrollo de este tipo de fuente energética, entre 40 y 80 millones de personas fueron desplazadas (no existen datos específicos sobre eso, pero sí sobre los kilowatts producidos). Sin embargo, hay un número considerable de proyectos en curso a pesar de las experiencias negativas de los últimos años; tales son los casos de la India y el Brasil. La sequía se extiende en zonas específicas, como el Sahel o Asia central. Se prevé no menos de 200 millones de migrantes climáticos para la mitad de este siglo, si el proceso sigue como hoy. Las consecuencias sociales y políticas de la falta de agua podían ser graves, pues se podrían provocar guerras por su disputa.

En resumen, no se trata de cualquier problema, sino de un asunto central para el futuro del planeta y de la especie humana. La responsabilidad es colectiva y las soluciones son urgentes. El gran desafío para el planeta es la necesitad de producir un nuevo paradigma de desarrollo humano en el planeta. El capitalismo está destruyendo la base misma de su propia existencia y por eso ha terminado su ciclo histórico. Él puede todavía provocar daños aún más graves. Las soluciones parciales que desde su lógica se propone, tales como la producción masiva de agro-combustibles, la privatización de los elementos esenciales a la vida, como el agua o las semillas, la mercantilización generalizada de la naturaleza para introducir la ley del mercado supuestamente reguladora de la ofer- 
ta y de la demanda, no bastarán para restablecer la armonía entre la tierra y los seres humanos.

El nuevo paradigma o orientación fundamental es la búsqueda del Bien Común de la Humanidad o del Buen Vivir, implicando una relación de respecto con la tierra, privilegiando el valor de uso sobre el valor de cambio, sin apropiación privada ni de las riquezas naturales, ni de la plusvalía sobre el trabajo, estableciendo procesos democráticos, no solamente en la política, sino en todas las instituciones (incluyendo económicas) y en todas las relaciones sociales (también entre hombres y mujeres) y promoviendo la interculturalidad (DAIBER; HOUTART, 2012). Solo la convergencia de los movimientos populares, sociales y políticos, será capaz de realizar un objetivo de esta naturaleza.

\section{REFERENCIAS}

ÁlVAREZ, Víctor. La trampa de la "Economía Verde". América XXI, Caracas, n. 86, p. 14-15, jun. 2012. Disponible en: <http:// www.americaxxi.com.ve/uploads/pdf/revista86.pdf>. Consultado el: 20 jun. 2012.

AMATYA, Prokash; SEGUIN, Nathalie. Political will: not present at the negociations on water and sanitation. Outreach, 19 jun. 2012. Disponible en: <http://www.stakeholderforum.org/sf/outreach/index.php/rio/112-dialogue4/1019-dialogue4item9>.

CLARIN, Buenos Aires, 6 jul. 2012.

DAIBER, Birgit; HOUTART, François. Un paradigma poscapitalista: el bien común de la humanidad. Panama: Ruth Casa Editorial, 2012.

DECLARACIÓN de la Conferencia internacional de Pueblos Indígenas sobre Desarrollo Sostenible y Libre Determinación. 20 jun. 2012a. Disponible en: <http://codpi.rio20.net/2012/06/20/declaracion-de-la-conferencia-internacional-de-pueblos-indigenas-sobredesarrollo-sostenible-y-libre-determinacion/>.

DECLARACIÓN de la Cumbre de los Pueblos frente al G20. 22 jun. 2012b. Disponible en: <http://www.coaliciong20.org/?p=1166>.

TAVARES, Joana. Agronegócio, agrotóxico e "agrocâncer”. Brasil do Fato, São Paulo, ano 10, n. 486, p. 3, jun. 2012. Edição Es- 
pecial - Agrotóxicos. Disponible en: <http://www.brasildefato. com.br/node/9847>.

THEMATIC SOCIAL FORUM. Another future is possible: texts drafted on the basis of the findings of the Thematic Groups of the Thematic Social Forum. Porto Alegre, 20 jun. 2012. p. 15-16.Disponible en: <http://rio20.net/en/iniciativas/another-future-is-possible>.

TSENIKLI, Sofia. An oceans rescue plan at Rio. Outreach, 19 jun. 2012. Disponible en: <http://www.stakeholderforum.org/sf/outreach/index.php/rio/112-dialogue4/1021-dialogue4item1>. 